\title{
Desinstitucionalização em saúde mental e práticas de cuidado no contexto do serviço residencial terapêutico
}

\author{
De-institutionalization of mental health and care practices \\ in the context of home-based care
}

Ana Karenina de M elo Arraes Amorim ${ }^{1}$

Magda Dimenstein ${ }^{2}$

${ }^{1}$ Departamento de

Psicologia, Universidade

Potiguar (UnP). Av.

Salgado Filho 1600, Lagoa

Nova. 59056-000 Natal

RN. akarraes@terra.com.br.

2Programa de Pós-

Graduação em Psicologia Social, UFRN.
Abstract In Brazil, the home based care services (HCS) are considered strategic and essential in the de institutionalization process of patients who passed years in psychiatric hospitals and lost their family and social links. However, this service faces a series of problemsand challengesin the wider context of health care. This article seeks to analyze some of these problems and challenges based on the experience of the home-based care service in $\mathrm{N}$ atal - $\mathrm{RN}$ and on the literature in this field. Proposed on the basis of the idea that the encounters between insanity and city are potent destructors of the "asylum logic", these home-based care services put in question the current healthcare model, claiming to destruct the rigid and hegemonic forms of residence and care. The aim of this article is to discuss this "asylum logic" that surpasses the limits of the concrete insane asylum penetrating some daily practices of the substitute services, taking advantage of the weak articulation between the mental health services. The lack of a strong connection between the home-based care service and the psychosocial care center allows this logic to operate through day-by-day bio-political devices. Thus, we discuss the risks of this logic taking over and indicate some possibilities of avoiding this, defending a care model allowing for potent meetings with the city and for the construction of "affectionate networks" producing life and liberty.

Key words Deinstitutionalization, M ental health, Therapeutic homes, Care practices
Resumo Osserviços residenciaisterapêuticos(SRT) no Brasil são considerados estratégi cos eimprescindíveis no processo de desinstitucionalização de egressos de longas internações psiquiátricas que perderam vínculos sociais e familiares. No entanto, muitos são os problemas e desafios que este serviço evidencia no contexto mais amplo da atenção à saúde. Este artigo procura analisar alguns desses problemase desafiosa partir da experiência do SRT de Natal, Rio Grande do $\mathrm{N}$ orte, e de contribuiç̧̃es da literatura do campo. Propostos com basena idéia de que os encontros entre loucura e cidade são potentes no sentido da desconstrução da "lógica manicomial", osSRT são problematizadores do model o de atenção em saúde vigente, pois exigem a desconstrução dasformas rígi das ehegemônicas de morar ecuidar. Pretende-se problematizar essa "lógica manicomial" que atravessa os limites dosmanicômios concretosese atualiza no cotidiano dos serviços substitutivos em certas práticas e na frágil articulação da rede de saúdemental. A falta de articulação efetiva entre SRT e Centro de Atenção Psicossocial (CAPS) dá lugar a dispositivos biopolíticos no cotidiano através dos quais essa lógica opera. Discutimos, então, os riscos de captura por esta lógica eindicamosalgumas das possi bilidades de desconstrução, defendendo uma clínica que possi bilite encontros potentes com a cidade e a construção de "redes de trabal ho afetivo" produtoras de vida e liberdade. Palavras-chave Desinstitucionalização, Saúdemental, Serviço residencial terapêutico, Práticas em saúde 
Introdução

A história da reforma psiquiátrica brasileira é um processo em construção e um projeto com diferentes versões. A mais atual, que fundamenta as políticas de saúde mental, éa da desinstitucionalização entendida como desconstrução de saberes, discursos e práticas psiquiátricos que sustentam a loucura reduzida ao signo da doença mental e re forçam a instituição hospitalar como a principal referência da atenção à saúde mental ${ }^{1}$. N o entanto, quando analisamos a realidade da saúde mental brasileira, observamos que existe uma série de impasses que dificultam a concretização deste proje to de desinstitucionalização. Dentre esses impasses, encontram-se a redução da reforma a um processo de desospital ização sem a real desmontagem do hospital psiquiátrico e o deslocamento completo da atenção em saúde mental para serviços substitutivos territoriais integrados à rede de saúde mais ampla. Esta dificuldade gera, dentre outras problemáticas, o fato de que os serviços que deve riam ser substitutivos ao hospital psiquiátrico não atendem à demanda em saúde mental da população, colaborando para a existência de discursos segundo os quais a reforma psiquiátrica tem promovido desassistência e justificando a manutenção da estrutura psiquiátrica tradicional. Temos, então, que a desinstitucionalização, como processo efetivo de desconstrução de saberes e práticas manicomiais, ainda se coloca como um projeto cujas bases precisam ser mais bem desenvolvidas.

Diante dessa realidade, procuramos lançar nossos questionamentos em relação ao mais recente dispositivo no processo de reforma psiquiátrica brasileira: o serviço residencial terapêutico (SRT). O M inistério da Saúde ${ }^{2}$ indica que a criação de serviços residenciaisterapêuticoséimprescindível para a substituição dos leitos em hospitais psiquiátricos por que estes serviços visam a oferecer condições de vida para aqueles com histórico de longas internações psiquiátricas, moradores de rua e egressos de instituições penais e manicômios judiciários, ou seja, pessoas com vínculos familiares e sociais comprometidos ou inexistentes. Para tanto, a Portaria no $106 / 2000^{2}$ estabelece a vinculação decada SRT a um serviço de referência, quese configura como local de tratamento para os seus moradores. Este serviço de referência pode ser um CAPS (Centro deAtenção Psicossocial), um serviço ambulatorial especializado em saúde mental ou ainda uma equipe de saúde da família com apoio matricial em saúde mental.

Os SRTs "visam os processos de autonomia, de construção de direitos, de cidadania e de novas possibilidades de vida para todos" e devem garantir "o acesso, o acolhimento, a responsabilização e a produção de novas formas de cuidado do sofrimento"2. Sendo assim, configuram uma modalidade de serviço que pode ser considerada avançada no sentido da desconstrução da loucura como signo de aprisionamento, periculosidade e isolamento, pois aposta na convivência urbana dos"loucos" como cidadãos e busca concretizar a efetiva substituição dos manicômios e a liberdade de exinternos de circular pela cidade.

$\mathrm{Na}$ realidade específica da saúde mental no município de $\mathrm{N}$ atal ( $\mathrm{RN}$ ), foi implantado em maio de2005 o primeiro serviço residencial terapêutico, de modo a despertar nosso interesse sobre o processo de desinstitucionalização em curso nestecontexto específico, tendo em vista queéuma primeira experiência com este tipo de serviço na região e que, como tal, seria potencialmentelivre de cronicidades e repleto de desafios em sua implantação e funcionamento.

Considerando as características e a concepção de SRT tal como proposto pelo M inistério da Saúdeeas peculiaridades da experiência do SRT deN atal, esse trabalho visa a problematizar as práticas de cuidado produzidas no seu cotidiano de modo a construir novas possibilidades de vida para usuários e técnicos e como estas práticas de cuidado, em alguma medida, podem também ser capturadas pela lógica manicomial, reproduzindo-a eimpedindo a construção de vida para além do hospital, dos muros institucionais e dos serviços de saúde em geral. Colocamos, assim, em discussão, a clínica que se pode desenvolver nesses serviços e al gumas das problemáticas trazidas na literatura e outras queemergem da própria experiência do SRT deNatal que temos acompanhado, sabendo que esta modalidade de serviço lança o desafio da desconstrução das formas habituais e hegemônicas de morar ede cuidar eclinicar, considerando as imprevisibilidades que o encontro da loucura em sua estranheza e em suas formas institucionalizadas com a cidade traz para moradores e cuidadores ${ }^{3}$.

\section{O processo de desinstitucionalização ea proposição dos serviços residenciais terapêuticos}

0 processo de reforma psiquiátrica vem sendo construído no Brasil há vários anos e tem como um dos seus pilares principais a desinstitucionalização ${ }^{4,5}$. No entanto, ao longo do processo histórico de construção da reforma, muitas são as concepções e as práticas de desinstitucionalização, de 
modo que os projetos de reforma não são homogêneos e o que efetivamente demarca uma real distinção entre os projetos de reforma, [...] éa forma do lidar prático e teórico da desinstitucionalização, conceito este que sofre metamorfose substancial e que abre novas possibilidades para o campo da reforma 4 .

Consideramos aqui a desinstitucionalização como desconstrução de saberes e práticas psiquiátricas, perspectiva que fundamenta o movimento de reforma psiquiátrica e a política de saúde mental brasileira, inspirada na proposta da psiquiatria democrática italiana. Essa versão da desinstitucionalização é caracterizada pela crítica epistemológica ao saber médico psiquiátrico, na qual o sentido de cidadania ultrapassa o do valor universal para colocar em questão o próprio conceito de doença mental que determina limites aos direitos dos cidadãos ${ }^{6}$.

$\mathrm{N}$ esse sentido, o movimento de reforma psiquiátrica brasileira busca a desconstrução da realidade manicomial - para além da "queda dos muros manicomiais" em sentido físico - e a construção de novas realidades, segundo novas bases epistemológicas, políticas esociais, operando transformações de toda uma cultura que sustenta a violência, a discriminação e o aprisionamento da loucura. Para tanto, é necessária a desmontagem da cultura e da estrutura psiquiátrica que separou "um objeto científico, a doença, da existência global complexa e concreta dos pacientes e do corpo social" ${ }^{6}$. 0 primeiro passo nessa desmontagem seria renunciar à perseguição da cura, na relação problema-solução, tomando como objeto a existência-sofrimento. Assim, a ênfase não é mais colocada no processo de cura no sentido da vida produtiva, mas no projeto de "invenção da saúde" e de "reprodução social do paciente" através da utilização das formas e dos espaços coletivos de convivência dispersa ${ }^{6}$. A saúde passa, então, a ser entendida não mais a partir de parâmetros de bem-estar definidos desde princípios biomédicos e regulados pelo Estado, mas como produção da vida possível e com sentido para os sujeitos em suas singularidades nos diferentes espaços de sociabilidade e solidariedade em que circulam.

Assim sendo, a concepção de território é fundamental na construção do cenário estratégico da saúde mental. 0 território é uma "força viva de relações concretas e imaginárias que as pessoas estabelecem entre si, com os objetos, com a cultu$\mathrm{ra}$, com as relações que se dinamizam e se transformam" ${ }^{1}$. 0 trabalho no território não seria um trabalho de promoção de saúde mental, mas de "invenção de saúde". Isso porque o que habitualmentesechama decomunidadepodeser "um grande deserto, pode ser o lugar da anomia", enquanto no território existem forças vivas e não forças mortas [...] existem os homens que buscam trabalhar sobre as inovações sociais [...]. Então, o saber do paciente, o saber do sujeito paciente, o saber dos familiares, esses saberes que existem no território devem ser incorporados em nossas práticas?

Com base nessas idéias de desinstitucionalização como desconstrução e de território é que o modelo de atenção em saúde mental brasileiro foi proposto no sentido de expandir e consolidar uma rede de atenção extra-hospitalar, de modo a atender as demandas territoriais específicas sem desassistir e indo além da pura desospitalização. Esta redehojeéconstituída deunidades básicas de saúde (UBS), centros de saúde, serviços de prontoatendimento, ambulatórios, centros de atenção psicossocial (CAPS) eserviçosresidenciaisterapêuticos(SRT).

Nesta rede de serviços, destacamos os SRT por constituírem os mais recentes dispositivos terapêuticos oferecidos na rede, sendo reconhecidos como avanço no processo de reforma psiquiátrica brasileira. No entanto, caracterizando-se como serviços que devem ser "prioritariamente" locais de moradia e não de tratamento, ficando este sob a responsabilidade dos outros serviços substitutivos da rede, os SRT produzem questionamentos ao modo de funcionamento da mesma, assim como apontam desafios nos processos de produção de saúde que se desenvolvem diretamente nele ou a partir dele.

Para pensar tais desafios, é preciso considerar que, apesar do modelo assistencial proposto pelas políticas de saúde mental nacional, regionais e locais e dos avanços no sentido da desospitalização com a implantação dos serviços acima destacados e a expansão da rede, quando analisamos o processo de reforma psiquiátrica brasileira como um todo, encontramos uma série de impasses que obstaculizam o processo de desinstitucionalização como real desconstrução.

Dentre os impasses, está a chamada "institucionalização do CAPS"8, problemática que pode ser estendida para qualquer tipo de serviço substitutivo da rede de saúde mental. Se por um lado esta institucionalidade é necessária à legitimidade destes serviços na rede de saúde, por outro, se corre o risco que ela se transforme em institucionalização crônica e cronificada, reproduzindo o manicômio do qual quer escapar. Há, por exemplo, a repetição de certas práticas tutelares e absorção de demandas que "deveriam" ser atendidas por outros dispositivos da rede. A cada dia aumenta o número de usuários que freqüentam o CAPS, forçandonos a questionar como construir outros projetos de vida que não dependam dos serviços e como 
escapar das práticas tutelares sem desassistir, bem como criar fluxos de encaminhamentos, como criar efetivamente uma rede de assistência.

A questão da inexistência ou da fragilidade de uma efetiva "rede" de atenção em saúdee, em especial, em saúde mental, pode ser observada na desorganização de várias portas de entrada e a falta de portas de saída, de modo que a rede não se faz, pois características essenciais como a descentralização e a conectividade não se operam e o que vemos é "um conjunto de pontos ligados frágil e burocraticamente" 8 . I sto por que se temos uma organização de serviços que se configura com uma forte referência central, sem um fluxo de encaminhamento e que não é objeto de pensamento e transformação permanentes, o que se configura é uma rígida estrutura "em grade" enão uma rede em que tenha lugar a liberdade e a invenção da saúde. Tal desarticulação da rede reflete-se de modo mais específico na relação do próprio SRT com o CAPS de referência, trazendo diversos problemas para a atenção aos usuários. $N$ a realidade de $N$ atal, por exemplo, podemos observar dificuldades na construção de espaços de comunicação entre os técnicos dos serviços, o que impede as necessárias discussões acerca do modo como estes moradores devem ou não ser acompanhados pelo CAPS, bem como acerca da regularidade e freqüência a tal serviço para participarem de suas atividades ereceberem medicação, sabendo-se que há uma equipe de cuidadores no SRT.

Assim, pela precariedade de espaços de discussão entre os serviços, há a falta de clareza em relação às atribuições de cada serviço para com aqueles usuários, produzindo uma precária co-responsabilização pelo cuidado destes que, enquanto moradores do SRT, são considerados usuários "extras" pelo CAPS, contrariando a própria orientação oficial do Ministério da $\mathrm{Saúde}^{2}$ a respeito da articulação desses serviços.

Assim, observamos que a passagem de um regime tutelar para outra forma de cuidado que proponha a produção de práticas de liberdade constitui um processo cheio de atravessamentos, de modo que mesmo nos serviços substitutivos sobrevivem condutas e posicionamentos que revelam não mais uma estrutura manicomial, mas idéias manicomiais que ainda circulam e se fazem presentes nos serviços de saúde mental e se atualizam "em práticas/ discursos de exacerbada medicalização, deinterpre tações violentas, de posturas rígidas e despóticas" 9 .

Por isso, ao analisarmos este processo de desinstitucionalização da loucura no âmbito dosSRT, não se pode pensar apenas no campo técnico-assistencial, mas também nas forças em jogo nos campos sociocultural e político-jurídico, que conferem complexidade a esse processo e nos quais uma lógica manicomial parece se operar de modo efetivo e amplo.

Lógica manicomial e dispositivos

biopolíticos no cuidado em saúde mental

Diante da complexidade do processo de desinstitucionalização e das problemáticas em torno dele, é preciso considerar a existência de uma lógica manicomial que atravessa as mais diferentes realidades no campo da saúde mental, dizendo respeito ao caráter asilar, segregante e tutelar dos processos de subjetivação na contemporaneidade, para além desse campo específico deinteresse. Esta lógica manicomial parece estar presentenos diferentes espaços e tempos, configurando diferentes formas de controle da vida que superam as formas disciplinares de aprisionamento dos $\operatorname{corpos}^{10}$.

Para realizar a análise da lógica manicomial em diferentes campos, as contribuições de M ichel Foucault sobreo biopoder eaquelas de Gilles Deleuzee Félix Guattari sobre a chamada sociedade de controle e os processos de subjetivação na contemporaneidade capitalista colocam-secomo interessantes e potentes na produção de reflexões.

A noção de biopoder no sentido do "poder sobre a vida" 11 diz respeito à gestão da vida incidindo já não mais sobre os indivíduos (como no sistema disciplinar), mas sobre a população que passa a ser controlada, regulada em seus processos biológicos (tais como a reprodução, a natalidade, a mortalidade e o nível de saúde). Assim, de acordo com as idéias de Foucault ${ }^{10}$, enquanto a disciplina controla cada indivíduo em seu corpo e em seus desejos nas fábricas, prisões e manicômios, o biopoder, ou poder de regulação da vida, administra o homem enquanto espécie viva nas cidades, na população, nas diversas instituições. Há, com a "derrubada dos muros" no sentido físico, uma diluição dos "muros" e o transbordamento da lógica de poder para outros setores da vida, fazendo-nos "prisioneiros a céu aberto"12. É nesse sentido que Deleuze sugere que os poderes sobre a vida encontram-se diluídos hoje na chamada "sociedade de controle", através do cruzamento entrea norma da disciplina ea norma da regulamentação (operada pelo biopoder), e em relação aos quais devemos responder com as "potências de criação da vida" ${ }^{13}$.

$\mathrm{Na}$ "sociedade de controle" ${ }^{13}$, controles implícitos da vida nos atravessam de modo insistente e insuspeito. E eles dizem respeito, sobretudo, à relação humana com o tempo e o espaço de existên- 
cia. Constatamos diariamente a nossa insuficiência para acompanhar a sua vel ocidade, somos chamados a correr atrás de um futuro que parece escorregar. E, nessa sensação de insuficiência, somos tentados a utilizar diferentes formas de controle do tempo, seja de ordem tecnológica e material (máquinas do tempo), seja de ordem relacional (rotinas, horas marcadas, controle da duração de quase todos os acontecimentos a que se está sujeito diariamente).

No mesmo sentido, em relação aos espaços de existência, a lógica da globalização capital ista atual leva-nos a transcender territórios e a estar conectados com a diversidade ea multiplicidade de culturas elugares, de modo que podemos ter acesso a diferentes territórios identitários sem que estejamos fixos em nenhum deles. Porém, o que é amplamente ofertado pelo mercado global capitalista são formas de fixar identidades, através de estratégias demídia, desuportes tecnológicos, deaprisionamentos teóricos e de pensamento. Dentre tais mecanismos de aprisionamento, destacamos aqui as fixações identitárias na figura do doente mental como signo de periculosidade, que sustenta a lógica manicomial em nossa cultura.

Assim, os mecanismos de controlee poder não estão mais evidentes ou claramente delimitados como nas instituições totais psiquiátricas tradicionais estudadas por Goffman ${ }^{14}$, mas estão presentes nos controles implícitos de espaço e tempo a que todos estão sujeitos nos processos de fabricação de subjetividades na contemporaneidade $\mathrm{e}^{15,16} \mathrm{e}$ que se colocam de modo peculiar na realidade da atenção à saúde mental brasileira.

Situando tal lógica na atenção em saúde mental, observamos que, seja na rotina diária de atividades nos serviços substitutivos, seja no tempo de institucionalização no hospital psiquiátrico ou nestes serviços ou no tempo "fora" dos serviços, a experiência e a relação que se estabelece com o tempo se colocam de modo que há uma espécie de "controle da vida pelo tempo" que liga de modo importante os usuários aos serviços e que os separa da vida "lá fora", da vida na cidade para além das "Iinhas de ônibus" (rotineiramente utilizadas pelos usuários e que constituem uma das poucas formas de contato com a cidade para além da casa e do serviço).

Dessa forma, épertinentequestionarmos como certos limites de tempo (permanência no serviço durante a semana, freqüência ao serviço, período destinado às atividades desenvolvidas), que são estabel ecidos pelos serviços através do exercício dos saberes e poderes que nele circulam, funcionam de modo a deixá-los numa espécie de "dependência" da instituiçãa ${ }^{8}$ que não raro se justifica, no discurso profissional, pela "dependência" aos medicamentos e ao acompanhamento médico.

Em relação à delimitação do espaço, observamos que os usuários de serviços extra-hospitalares, sobretudo aqueles de regime semi-intensivo, percebem suas casas como "prisões de fim de semana", que os protegem das ameaças da vida nas cidades equea "vidalivre" ou a vida possível parece ser encontrada no contexto do serviço, de modo que apenas dentro dos muros institucionais é possível existir. Assim, a vida que é produzida de alguma maneira nos serviços parece não ter extensão para a vida "lá fora". Diantedisso, indagamos: como fazer acontecer esta extensão, ou melhor, como fazer acontecer o "livre trânsito" dessas pessoas na vida comum das cidades, nos diferentes espaços e tempos de vida? Ou antes, que "linhas" são essas que as amarram aos serviços e as impedem de circular livremente pelas cidades no trânsito para casa?

A existência dessa forma de depen dência marcada pela temporalidade e pela espacialidade parece evidente também nos usuários que são moradores de SRT quando, tal como ocorre em Natal, as atividades que exigem circulação pela cidade são restritas e dependem da disponi bilidade dos técnicos do SRT em acompanhá-los ou quando é estabelecida uma regularidade de participação nas atividades do CAPS do território e de busca pela medicação que os obriga a freqüentar esteserviço sem que isso esteja claramente atrelado aos projetos terapêuticos, o que certamente resultaria em diferentes arranjos em função das necessi dades de saúde singulares a cada um.

Esta desarticulação em relação aos projetos terapêuticos de cada morador fica evidente, pela recusa ou insatisfação de alguns moradores em freqüentar o CAPS, por se sentirem "presos" lá dentro ou por não verem sentido no que fazem no serviço. Além disso, tal recusa parece colocar a necessidade de se pensar novas práticas de cuidado destinadas aos usuários do CAPS de modo geral. Práticas estas que devem ser discutidas junto aos cuidadores do SRT ou aos familiares dos usuários em geral no sentido de, por exemplo, se desenvolverem "fora" dos murosfísicos do CAPS, na circulação pela cidade, o que poderia permitir a construção de projetos terapêuticos que efetivamente atendessem as necessidades de saúde de cada usuário vinculadas aos seus "projetos de felicidade" ${ }^{17}$.

Diante dessa constatação, parecenecessário que todos os envolvidos estejam atentos a estas formas decaptura biopolítica que sutilmente se opera no cuidado a esses usuários, de modo a fazer a clínica se movimentar. Para tanto, não seria neces- 
sária a criação de parcerias e espaços de discussão efetivos sobre as peculiaridades do trabalho e os projetos terapêuticos de cada usuário? Em que medida esses projetos estão vinculados aos seus "projetos defelicidade"17? A vinculação do SRT com - CAPS implica um trabalho atento a questões como estas e que respeite as necessidades de saúde singulares a cada morador, o que exige a criação de alternativas de cuidado que escapam ao modelo terapêutico institucionalizado de CAPS.

Quando consideramos esta realidade específica do SRT, que é ao mesmo tempo uma casa na qual os moradores, como em qualquer casa, devem poder circular a qualquer tempo por diferentes espaços sociais e públicos, podemos pensar que esses mecanismos de controle e as estratégias de resistência à lógica manicomial vão incidir sobreo cotidiano dos moradores e cuidadores, nas relações que estes estabelecem entre si, nos mais variados âmbitos da vida que estão construindo juntos e também sobre as práticas de cuidado em saúde que ali estão se realizando. É nesse sentido que os SRT têm se revelado como problematizadores da atenção em saúde mental e, como tal, têm mobilizado uma série de questionamentos relativos à clínica e aos modos de morar e habitar, tais como: queclínicaépossível nestecontexto residencial sem cair nas práticas tutelares? Q ue acolhimento e que formas de cuidado se fazem nesse novo modelo sem aprisionar a vida? Como se fazem essas formas de cuidado no transitar cotidiano entre casa e cidade e tudo que a vida comum comporta?

Temos, assim, uma série de questões que exigem análise sobre a cidade, como espaço em que o cotidiano se faz e em que os diversos processos de subjetivação se produzem; sobre os modos de morar como formas de lidar com o espaço e o tempo de vida cotidiana que, tradicional mente, são naturalizados em modelos privatizados, impermeáveis e higiênicos de habitar e sobre a clínica como um conjunto de equipamentos teóricos e práticos de cuidado e de produção de saúde, que tradicional e modernamente têm se operado e se naturalizado em model os também privatizados, impermeáveis e higiênicos, sem espaço para a criatividade na construção de novas práticas e modelos teóricos ${ }^{18}$.

Cidadee subjetivação: (des)construção de modos de morar e clinicar

$\mathrm{Na}$ análise das questões que envolvem a cidade, os modos de morar e clinicar que nossa problemática exige, consideramos a subjetividade no sentido do seu processo deprodução, mais precisamentecomo processo de subjetivação, que perpassa o pensamento de Gilles Deleuze e Félix Guattari ${ }^{15,}{ }^{16}$. Ou seja, interessa-nos a produção ou fabricação de subjetividade no contexto capital ista da atualidade, com as forças deordem política, social, ética e estética que caracterizam o momento contemporâneo.

Colocando a subjetividade sob o signo da exterioridade, Guattari ${ }^{19}$ propõe a idéia de cidade subjetiva. N esta proposição, a cidade e a subjetividade seriam uma mesma coisa, desde que ambas fossem remetidas à dimensão da exterioridade e virtualidade que Ihes é comum, naquilo que ambas comportam de meios a serem explorados, trajetos de vida a serem percorridos, devires a serem inventados. A cidade subjetiva representaria essa processualidade da produção subjetiva no sentido da invenção que se opera na coletividade e não da serial ização, homogeneização e reprodução da vida.

N essesentido, Baptista ${ }^{18}$ propõequepensemos na cidade como espaço de subjetivação em que a heterogeneidade, o imprevisível, as impurezas, as estranhezas colocam desafios e exigem invenções cotidianas aos modos de morar e habitar, cuja porosidade os distancia de um ato humano fixado e de um modo particular de operar a existência que define a subjetividade como atributo individual. Tal porosidade permite a entrada dos paradoxos e contradições do espaço público, ameaçando, assim, certas modalidades de gerência da saúde e do sofrimento que caracterizam a lógica manicomial e exigindo a criação de novas formas de cuidar e de morar, não mais calcadas em modelos devigilância do íntimo e em regimes detutela legitimados pela soberania dos saberes, ou em modos de morar restritos à casa como espaço íntimo impermeável que bloqueia os sentidos da diversidade e inibe as construções e narrativas coletivas.

Considerando esta idéia da cidade como espaço de subjetivação, pensamos, então, no encontro entre loucos e cidade, no qual estas experimentações podem se fazer. Segundo Amarante ${ }^{4}$, baseado nas reflexões de Basaglia, o louco, expropriado de seus direitos, desua família, desua comunidade de origem e do convívio com a sociedade, deve ter na cidade o espaço real "dos processos de validação social dos sujeitos". A proposta basagliana defende então a necessidade do encontro entre a loucura e a cidade, entendendo esta como "território"1. E, nesta proposta, tal encontro deve ser orientado pela desinstitucional ização eatravessado pelas práticas de cuidado promovidas pelos serviços substitutivos, mas também por outras estratégias, práticas e redes de cuidado e equipamentos sociais que possam vir a ser desenvolvidas na cidade, nos espaços micropolíticos de vida, como extensão ou 
não daquelas práticas dos serviços. Aqui lembramos o acompanhamento terapêutico como estratégia que tem se revelado interessante no processo de desinstitucionalização construído a partir de dispositivos residenciais por basear a terapêutica na potência deste encontro da loucura com a cidade, possibilitando uma "clínica em movimento"20.

Atentando especificamente para os SRT, as práticas de cuidado podem ser pensadas como "práticas cotidianas" ${ }^{21}$ e, por conseguinte, é preciso considerar também o que se poderia chamar de "risco de captura" manicomial, no sentido já exposto, a partir dos modos de morar e cuidar que são desenvolvidos nesta casa. Enquanto um dispositivo que se pretende antimanicomial por tentar promover a construção da vida de pessoas que foram cronicamenteinstitucionalizadas, os SRT eespecificamente os modos de morar e as práticas de cuidado que são construídos, neles e a partir deles, no encontro com a cidade, podem operar ou não na contramão da lógica manicomial. Daí al gumas questões emergem e merecem atenção no cotidiano de cuidado desta realidade: o que este en contro dos loucos com a cidade pode comportar de virtualidade, de possibilidade de novos traçados de vida, sabendo que 0 manicômio se estende à cidadeem suas linhas também virtuais? Como eles vão atravessar, viver na cidade e circular no cotidiano urbano com os manicômiosinvisíveis existentes? Quevisibilidadeserá possível construir para arrancar-Ihes das invisibilidades manicomiais? Será o movimento desses moradores um "pseudo-movimento" 12 que os fará permanecer num mesmo lugar, num nomadismo apenas físico e não subjetivo? 0 desafio da clínica que se opera nestes serviços parece ser o de sondar quetipo demeio uma cidadeainda podevir a ser, que afetos ela favorece ou bloqueia, que trajetos ela produz ou captura, que devires ela libera ou sufoca [...] que potências fremem nela eà espera de quais novos agenciamentos ${ }^{12}$.

Desta forma, os SRT em curso no país enfrentam o peculiar desafio de pensar se é possível uma "clínica do morar" 18 que traz em seu lastro questionamentos aos tradicionais equipamentos teóricos psi e aos novos espaços inspirados na desinstitucionalização, que devem partir da desnaturalização do morar e da própria clínica e da abertura às experimentações que estes novos dispositivos da luta antimanicomial exigem e convidam na tarefa de produzir saúde.
Cuidado e invenção de saúde no contexto dos SRT: contribuições à clínica

Considerando a realidade dos SRT, Baptista ${ }^{3,18}$ indaga como as experiências que se processam nestes dispositivos podem interpelar, fazer deriva, trazer reflexões para as propostas clínicas já existentes. Ou seja, os SRT constituem um convite a pensar a clínica como política e vice-versa, fazendo emergir a potencialidade crítica da clínica em saúde mental.

Tradicionalmente, nos campos da formação e da prática clínica em saúde mental, tem-se a reprodução acrítica das dicotomias sujeito/objeto, teoria/prática, interior/exterior, consciente/inconsciente, clínica/política, entreoutras. E esses campos parecem fundados na crença em uma postura neutra, que busca a correção e conversão homogeneizante do que é desviante, do que está fora da norma, através deoperações deestabilização eestancamento do sofrimento e do estranho que move o desejo e a criação da vida. Têm-se, assim, modelos de reprodução do mesmo no que diz respeito à produção subjetiva quese faz na clínica, modelos que se colocam "como instrumentos biopolíticos, por encerrarem em si o poder de separar a vida do vivo, 0 desejo do ser. Subordinação do vir a ser ao ímpeto da prescrição de modos de existir no mundo"22.

No que se refere aos SRT, a clínica tem sido baseada na estratégia do acompanhamento terapêutico que se fundamenta na "clínica das psicoses" segundo referenciais psicanalíticos ${ }^{20}$. Assim, apesar deconstituir uma estratégia potente, o acompanhamento terapêutico, assim referenciado, corre o risco de fazer a clínica prescindir das experimentações quando coloca como foco de intervenção uma "estrutura psíquica" a priori conhecida que responde como doença diante da realidade social com a qual precisa restabelecer o vínculo simbólico a todo custo. 0 sucesso terapêutico consiste, então, numa "solução de compromisso" traduzida como uma espécie de "acordo social" do desejo. Pode-seperder, assim, a potencialidade que o encontro da loucura com a vida comum na cidade tem a oferecer no sentido da desconstrução das formas de se viver em sociedade e da abertura ao novo quenenhum acordo simbólico podedar conta, pois o desejo transborda, não se "estrutura", não faz acordos, simplesmente deseja ${ }^{13}$.

N este sentido, a prática clínica pode ser pensa$\mathrm{da}$, em suas potencialidades criativas, como algo que se faz para além de settings predefinidos, técnicas préfabricadas, parâmetros de normalidades e subjetivações preconfiguradas. 0 encontro dosloucos com a cidade nos convida a pensar a clínica a 
partir do desejo de mundo que dissipa a dicotomia dentro-fora e permite a inserção de ambos num espaço compartilhado, possibilitando a produção desingularidades. Assim, a clínica constituiria uma ferramenta na invenção da saúde que se faz como cartografia dos modos de existir, ou seja, como o percorrer/acompanhar os espaços de ruptura epropagação do novo, o "aguçar as sensações, abrir 0 corpo, para torná-lo passagem de vozes/imagens demundo ainda não conhecido eexperimentado" 22 .

E para pensar essa "produção de saúde" no contexto dos SRT, parece nos pertinente o convite de Teixeira ${ }^{23}$ a refletir sobre as conseqüências micropolíticas das práticas de cuidado, considerando a possibilidade de operarem como autênticas "técnicas de reconstituição do laço social", sendo, portanto, amplamente coletivas. Ou seja, pensar em "produção de saúde" é pensar nas práticas de cuidado que são coletivamente desenvolvidas em "redes de trabalho social" a partir da experimentação e que possibilitam a vida ea saúde deindivíduos e populações.

Assim, entendemos que há uma indissociabilidade entre produção de saúde e de subjetividades, entre atenção, gestão e modos de existência movidos por forças que lutam contra a conservação e a reprodução das formas instituídas de viver e cuidar. Ou seja, há que se pensar a saúde "como experiência de criação de si e de modos de viver [...], isto é, novos sujeitos implicados em novas práticas de saúde" 24 .

Uma dessas novas práticas seria a do acolhimento queTeixeira ${ }^{23}$ propõequeseja pensada como "acolhimento-diálogo", como uma "técnica deconversa" que define a dimensão pragmática dos encontros, seus domínios de ação (emoções e afetos) e de significação, evidenciando "redes de trabalho afetivo". Tais "redes de trabal ho afetivo" seriam redes de produção de afeto, o que é "a própria produção deredes sociais, de comunidades, deformas de vida (biopoder), de produção de subjetividades (individuais e coletivas) e de sociabilidade".

Interessante destacar que, nesse sentido, na prática em "redes de trabal ho afetivo", há a necessidade da construção da confiança naquilo que, inspirado em Espinosa, Teixeir ${ }^{23}$ chama de "zona de comunidade", em que se coloca o desafio da alteridade, de aceitação do outro como legítimo outro e em que experimentamos novas intensidades, às quais fomos conduzidos pel os afetos aumentativos que anunciam, por sua vez, outros modos de existência, em que nos tornamos a causa última de nossas paixões, em queentramos plenamentena posse de nossa potência. Para Espinosa, a liberdade. Que outra forma de conceber as práticas de saúde seria mais coerente com a proposta dos SRT que essa? $\mathrm{N}$ o encontro com a cidade, é preciso que o acolhimento-diálogo se coloque como prática de saúde, de invenção de vida, de subjetivação e sociabilidade para os moradores, possibilitando a construção dessas "zonas de comunidade", desse "aumento da potência da vida" que éa própria liberdade.

\section{Consideraçõesfinais}

Diante dessas considerações, temos que o SRT coloca-se fundamentalmente como um dispositivo problematizador da atenção em saúde mental, exigindo a constante reflexão sobre as práticas e saberes em jogo no processo de desinstitucionalização em construção, sob pena de cairmos nas armadilhas da lógica manicomial, da "prisão a céu aberto"11.

Desta forma, o trabalho no SRT exige, sobretudo, a construção efetiva de redes de cuidado entre os serviços e entre diferentes equipamentos sociais, envolvendo a cidade com suas diferentes e potentes estratégias de cuidado. Isto implica a ampliação, a desnaturalização eo movimento constante do próprio trabalho em saúde, do que se entende por "clínica" a ser desenvolvida nos serviços, especialmente nos CAPS.

Temos, então, que os desafios colocados pelos SRT têm origem edirigem-se a diferentes espaços e atores envolvidos no cuidado de seus moradores, assim como exigem a construção efetiva de redes de cuidado e sociabilidade no trânsito dos moradores pela cidade. No entanto, isso parece depender de transformações e iniciativas em diferentes níveis.

Num nível macropolítico, está a necessidade de políticas públicas que exijam e possibilitem aos serviços a articulação com a vida "lá fora", na construção de redes de conexão e diálogo nos diferentes espaços onde cada usuário circula e constrói sua vida de modo a garantir a (des) construção permanente das práticas de cuidado de acordo com as necessidades específicas de saúde de cada usuário.

Num nível micropolítico, estaria a articulação entre os próprios técnicos, moradores e comunidade mais ampla, na produção/invenção do cuidado destes moradores. Aqui estaria talvez a própria condição de se pensar que este tipo de serviço trabalha para não ser mais necessário ao morador que, como uma pessoa qualquer na cidade, poderia buscar um "serviço de saúde" quando necessitasse. E, para isso, devem ir se desenvolvendo redes sociais de apoio e cuidado, construídas no cotidiano da cidade, com vizinhos, amigos ex-internos, namorados, técnicos que viraram amigos acolhe- 
dores, comerciantes, motoristas de ônibus, entre outros, multiplicando o cuidado na vida de todose cada um.

Um desafio seria, então, o de viabilizar que a circulação desses moradores na vida cotidiana, na cidademúltipla, diversa eimprevisível, comportea possibilidade de encontros "aumentativos de potência", produzindo liberdade e vida. E que essa viabilidade seja tomada como algo que espontaneamente vai se fazendo também para além e aquém das ações dos profissionais de saúde, desde que as intervenções por eles realizadas nesse contexto sejam constantemente objeto de reflexão, não se reproduzindo em "pequenos manicômios".

Assim, outro desafio que se coloca éa desconstrução e a desnaturalização das práticas profissionais a partir do acolhimento-diálogo no contexto dos SRT sem incidir na clínica tradicional, na escuta surda do modelo psicoterápico privado eindividual. Para tanto, é preciso fazer-se"zona de comunidade" ${ }^{23}$ que seria, como nos sugere Rolnik ${ }^{25}$, um "sofrer junto com" feito ao mesmo tempo de indiferença a tudo o que se aproxima da homogeneização (por exemplo, viver a queda como vítima) e de cumplicidade com todo equalquer movimento de entrega ede diferenciação.

0 trabalho em saúde seria efetivado, assim, como prática intercessora, entendendo com Deleu$\mathrm{ze}^{13}$ intercessor como algo ou al guém que funciona intercedendo a favor do estranho que nos habita, invocando-o e acolhendo-o, não como aquilo que há de monstruoso e perigoso, mas como aquilo que há de mais potenteem cada um. Assim concebido, 0 trabalho em saúdeexigeesta mudança em nosso modo de subjetivação, [...] esta abertura para 0 estranhoem-nós, queémais do queo simples respeito democrático pelo outro em seus direitos e deveres, pois é um desejo de se deixar afetar pelo outro, éum amor pela alteridade, pelo devir e a incerteza criadora ${ }^{25}$.

Desejamos assim que, na realidade de trabal ho nesses serviços residenciais, encontros com o estranho se façam, nos espaços porosos entre a casa e a cidade, os loucos e a casa, os loucos e a rua, os loucos e a cidade, os profissionais e os loucos, os profissionais e a rua, os profissionais e a casa, entre os loucos profissionais e a cidade, enfim, múltiplos encontros que vão constituindo em redes de trabal ho afetivo produtoras de vida e liberdade.

\section{Colaboradores}

AK Amorim trabalhou na concepção, redação do texto e pesquisa que dá subsídios ao artigo e M Dimenstein orientou a pesquisa teórica eempírica que fundamenta 0 artigo e trabal hou na redação e revisão final do texto. 


\section{Referências}

1. Amarante $P$, organizador. Psiquiatria social e reforma psiquiátrica. Rio de Janeiro: Fiocruz; 1994.

2. Brasil. M inistério da Saúde. Secretaria de Atenção à Saúde. Departamento de ações programáticas estratégicas. Coordenação Nacional de Saúde M ental. Residências terapêuticas: o que são, para que servem. Brasília: M inistério da Saúde; 2004.

3. Baptista LA, Zwarg MD, M oraes R. Reforma Psiquiátrica e os dispositivos residenciais: afirmações e impasses. In: M achado LD, Lavrador MC, Barros MEB, organizadores. Texturas da psicologia. Subjetividade $e$ política no contemporâneo. São Paulo: Casa do Psicólogo; 2001. p. 59-67.

4. Amarante P. 0 homem e a serpente: outras histórias para a loucura e a psiquiatria. Rio de Janeiro: Fiocruz; 1996.

5. Daúd Júnior N. Considerações histórico-conceituais sobre a instituição psiquiátrica no Brasil e a desinstitucionalização do "doente mental". In: Boarini ML, organizadora. Desafios na atenção á saúde mental. Maringá, SP: Eduem; 2000. p 31-64.

6. Rotelli F, Leonardis O, Mauri D. Desinstitucionalização, uma outra via. In: Rotelli F, Leonardis O, Mauri D, organizadores. Desinstitucionalização. São Paulo: Hucitec; 2001. p. 17-59.

7. Rotelli F. Superando o manicômio: o circuito psiquiátrico de Trieste. In: Amarante P, organizador. Psiquiatria social e reforma psiquiátrica. Rio de Janeiro: Fiocruz; 1994. p. 149-169.

8. Barros RB. Reforma Psiquiátrica Brasileira: resistências e capturas em tempos neoliberais. In: Conselho Federal de Psicologia. Loucura, ética e política: escritos militantes. São Paulo: Casa do Psicólogo; 2003. p. 196-206.

9. Machado LD, Lavrador MC. Loucura e subjetividade. In: Machado LD, Lavrador M C, Barros M EB, organizadores. Texturas da psicologia. Subjetividade e política no contemporâneo. São Paulo: Casa do Psicólogo; 2001. p. 45-58.

10. Foucault M. Vigiar e punir. Petrópolis: Vozes; 1984.

11. Pelbart PP. Vida capital: ensaios de biopolítica. São Paulo: Iluminuras; 2003.

12. Pelbart PP. A vertigem por um fio: políticas da subjetividade contemporânea. São Paulo: Iluminuras; 2000.

13. Deleuze G. Conversações. Rio de Janeiro: Editora 34; 1992.
14. Goffman E. Manicômios, prisões e conventos. São Paulo: Perspectiva; 1961.

15. Deleuze G, Guattari F. Mil platôs: capitalismo e esquizofrenia. Volume 1. Rio de Janeiro: Editora 34; 1995.

16. Deleuze G, Guattari F. Mil platôs: capitalismo e esquizofrenia. Volume 3. Rio de Janeiro: Editora 34; 1996.

17. Ayres JR. Cuidado e reconstrução das práticas de saúde. Interface (Botucatu) 2004; 14(8):73-92.

18. Baptista LA. Dispositivo Residencial e as Máquinas do Morar. In: Jacó-Vilela AM Cerezzo AC, Rodrigues HBC, organizadores. IV Encontro Clio-Psyché - História e M emória. Volume 1. Juiz de Fora: Clioedel; 2005.

19. Guattari F. Caosmose. São Paulo, Editora 34; 1992.

20. Palombini AL. Acompanhamento terapêutico na rede pública: a clínica em movimento. Porto Alegre: Editora UFRGS; 2004

21. Certeau M. A invenção do cotidiano. 1. Artes de fazer. Petrópolis: Vozes; 2004

22. Fonseca TMG, Kirst PG. O desejo de mundo: um olhar sobre a clínica. Psicologia \& Sociedade 2004; 16(3):29-34

23. Teixeira RR. As redes de trabalho afetivo e a contribuição da saúde para a emergência de uma outra concepção de público. In: Research Conference on Rethinking "the Public" in Public Health: Neoliberalism, Structural Violence, and Epidemics of Inequality in Latin America. San Diego: Center for Iberian and Latin American Studies (CILAS)/ University of California; 2004.

24. Benevides R, Passos E. A humanização como dimensão pública das políticas de saúde. Cien Saude Colet 2005; 10(3):561-571.

25. Rolnik S. Subjetividade e História. Revista Rua [periódico na Internet]; 2002. [acessado 2002 ago 29]. 1 [cerca de 6 p.]. Disponível em: http://www.labeurb. unicamp.br/rual_texto3.htm

Artigo apresentado em 06/07/2006

Aprovado em 13/09/2007

Versão final apresentada em 28/11/2007 